\title{
Dinâmicas e gestão do território, a cana-de-açúcar na bacia hidrográfica do Rio Brilhante - MS / Brasil
}

\author{
Dynamics and territory management, sugarcane in the Brilhante \\ River watershed - MS / Brazil
}

Patrícia Silva Ferreira, Doutoranda no Programa de Pós-Graduação em Geografia, Universidade Federal da Grande Dourados, Brasil, patiferrera@gmail.com

(1) https://orcid.org/0000-0001-8333-218X

Charlei Aparecido da Silva, Programa de Pós-Graduação em Geografia, Universidade Federal da Grande Dourados, Brasil, charleisilva@ufgd.edu.br

(1) https://orcid.org/0000-0002-5598-7848

Resumo: O incremento do setor sucroenergético no estado de Mato Grosso do Sul esteve inicialmente ligado ao projeto do ProÁlcool, esse subsidiava as agroindústrias para produção do álcool combustíveletanol. No período de 1979 a 1990 haviam apenas 9 usinas no estado e após o ano de 2015 o setor contava com 25 unidades. A produção e a área de cultivo da cana-de-açúcar quadruplicaram no período de 2003 a 2015. O presente estudo tem como objetivo mapear o uso e cobertura das terras e a evolução temporo-espacial da cana-de-açúcar na bacia hidrográfica do Rio Brilhante, uma importante bacia hidrográfica localizada na região centro-sul de Mato Grosso do Sul, Brasil. Para tanto utilizou-se de técnicas e de ferramentas de sensoriamento remoto associadas à trabalhos de campo, isso a fim de validar os resultados e identificar o uso e a ocupação das terras. Alerta-se sobre o uso e a ocupação exclusiva das terras com a melhor aptidão agrícola pela cana-de-açúcar, isso, no futuro, possivelmente suscitará danos às economias locais, e, no médio prazo, ao país vide a escolha por um padrão no qual a monocultura é prioritária.

Palavras-chave: uso das terras; aptidão agrícola; dinâmica e gestão territorial; SIG.

Abstract: The rising of sugarcane-eletrical sector at Mato Grosso do Sul State/Brazil has been entangled to the Brazilian ProAlcool project (this project has helped agroindustry sector to the ethanol fuel large production). There were only nine sugarcane plants between 1979 to 1990 at Mato Grosso do Sul State, but this number grew to twenty-five after 2015. The sugarcane production and the crop area multiplied by four between 2003 to 2015 . Thus, this research has aiming to spatialize the sugarcane land use as its temporal-spatial evolution at Brilhante River Basin (a relevant river basin of the centralsouth of Mato Grosso do Sul State). For this aim, the authors have explored remote sensing tools and technics allied with field work campaigns to be assured about the results which could identify the areas with the best sugarcane agricultural aptitude. This process of sugarcane regional spreading could bring economical damage to the study area and even Brazil as well because of the priority of the monoculture pattern.

Keywords: land use; agricultural suitability; dynamics and territorial management; GIS.

\section{Introdução}

No âmbito da ciência geográfica a compreensão do espaço geográfico e das relações entre os elementos que o compõem, analisados a partir do método sistêmico, permitiram avanços no processo de analise das inter-relações sob diferentes escalas e aspectos (Christofoletti, 1979; 1999), sempre visando demonstrar uma unidade 
dinâmica que incorpora aspectos baseados na estrutura e funcionalidade dos elementos físicos, biológicos e socioeconômicos (Ross, 1995).

A Teoria Geral dos Sistemas (TGS) a priori citada por Bertallanfy, originalmente publicada na década de 1930, é, posteriormente, difundida para diversas áreas do conhecimento científico. Na Geografia a teoria geossistêmica tem como principais precursores Sotchava (1978), Tricart, (1981), Christofoletti (1979, 1999), MateoRodriguez (2002, 2005), Monteiro (2000), Troppmair (2000), Bertrand (2004), Troppmair e Galina (2006), entre outros, que promoveram a utilização da abordagem geossistêmica como linha epistemológica e metodológica. No Brasil, o uso corrente em pesquisas de cunho ambiental ocorre principalmente a partir das décadas de 1960 e 1970. Para Silva (2006) tal fato deve-se à capacidade oferecida pela abordagem geossistêmica, "cujas preocupações residem no entendimento da estrutura, da dinâmica e da organização dos sistemas, bem como da influência direta e indireta de ações antrópicas nos processos que atuam em sua organização" (op. cit., p. 60), o que tem proporcionado, em certa medida, avanços na análise de questões ambientais.

Essa organização espacial dotada de níveis hierárquicos desempenha papel essencial para o seu funcionamento, uma vez que os elementos e as unidades que se interrelacionam estão sujeitas a processos de retroalimentação (Christofoletti, 1999), que podem influenciar direta e/ou indiretamente na sua dinâmica e no grau de homeostasia (Ross, 1994).

A organização espacial resultante da interação dos elementos componentes físicos da natureza (clima, topografia, rochas, águas, vegetação, animais, solos) possuindo expressão espacial na superfície terrestre e representando uma organização (sistema) composta por elementos, funcionando através dos fluxos de energia e matéria, dominante numa interação areal (Christofoletti, 1999, p. 42).

Nesse sentido, a bacia hidrográfica se apresenta como uma unidade de organização espacial, abrangendo todos esses elementos e suas interações (Santos, 2004), capaz, a partir de uma metodologia geossistêmica (Silva, 2006), de fornecer subsídios teóricos e práticos para a gestão territorial. A bacia hidrográfica se configura como um sistema aberto e em equilíbrio dinâmico, visto que há uma troca intensa de matéria e energia de fontes internas e externas (Christofoletti, 1999), manifestando simultaneamente os processos da dinâmica transformadora e estabilizadora (Sotchava, 1978). Nesse viés, Santos (2004) reforça o papel que as bacias hidrográficas exercem no contexto das mudanças ambientais e a caracteriza como uma das referências espaciais mais conceituadas em estudos do meio físico e que fornece subsídios para grande parte da legislação e planejamento ambiental e territorial, tanto no Brasil como em outros países.

Sob o ponto de vista do planejamento e gestão a bacia hidrográfica, como unidade de análise, incorpora parte de um conjunto de "unidades ambientais homogêneas" (Mateo-Rodríguez et al., 2011, p. 112), reunindo elementos naturais e sociais em um espaço definido, e ganha destaque por estender os limites políticos tradicionais 
(municípios, estados, países) direcionando, dessa forma, para uma abordagem sistêmica.

Para fins de gestão, o estudo da dinâmica da bacia hidrográfica, deve, fundamentalmente, ser realizado em uma estabelecida grandeza da escala temporal, uma vez que reflete os ajustes internos à amplitude dos eventos, mantendo sua integridade no funcionamento ou reajustando-se em busca de novas condições de equilíbrio funcional - homeostase -, assim como a caracterização espacial também é um aspecto pertinente ao estudo analítico.

No caso da bacia hidrográfica do Rio Brilhante, há em curso uma expansão do setor sucroenergético, que pode ser apontada como um vetor de transformação de grande amplitude, uma vez que ao ocupar grandes extensões de terra, dificilmente, os canaviais cedem espaços para outros usos (Frata e Faria, 2008), vejam-se os exemplos dos municípios com plantio de cana-de-açúcar nos estados de São Paulo e Goiás. Esse contexto torna-se assim o ponto central da discussão ora apresentada, a homogeneidade do uso das terras, o incremento do setor sucroenergético no estado de Mato Grosso do Sul em detrimento a um processo de gestão territorial plural e diverso.

\section{Metodologia}

A metodologia empregada baseia-se nos recursos geotecnológicos, envolvendo técnicas de aquisição, tratamento, armazenamento e análise espacial de dados via Sistema de Informações Geográficas (SIG). Os dados e as informações, adquiridas em institutos de pesquisas e órgãos públicos foram agregados em ambiente SIG. Segundo Fitz (2008) essa estrutura permite adquirir, armazenar, combinar, analisar e recuperar informações codificadas, espaciais ou não, possibilitando o tratamento de dados nos formatos vetoriais e matriciais, a combinação de funções de tratamento e processamento de imagens de sensoriamento remoto, a análise espacial de informações geográficas georrefenciadas e a construção de modelos digitais de elevação por meio de um único ambiente integrado e interativo.

Respeitando esses princípios, foram utilizados os softwares QGIS (QGIS, 2015) e SPRING 5.3 (INPE, 2014), georreferenciados no Datum padronizado para o Brasil, o Sistema de Referência Geocêntrico das Américas e seu ano de criação - SIRGAS 2000 - e sistema de coordenadas UTM (Universal Transversa de Mercator). Os produtos cartográficos (Figura 1) foram construídos sob a mesma base cartográfica na escala 1: 250.000. Nesta etapa dados espaciais foram adquiridos em instituições e institutos de pesquisa. Cita-se o Instituto Brasileiro de Geografia e Estatística (IBGE), o Serviço Geológico do Brasil (CPRM), o Projeto de Monitoramento da Canade-açúcar via imagens de satélite (CANASAT) do Instituto Nacional de Pesquisas Espaciais (INPE), a União da Indústria de Cana-de-açúcar (UNICA) e a Companhia Nacional de Abastecimento (CONAB). Destaca-se que esses são os principais órgãos e instituições responsáveis pelas estatísticas oficiais de área, da produção e produtividade das culturas agrícolas no país. Ademais, foram elaboradas informações 
de ordem primária, como a precipitação média anual, a declividade e o uso das terras. O processo técnico-metodológico utilizado será demonstrado mais adiante.

\section{1. Área de estudo, a determinação das classes e a síntese proposta}

A bacia hidrográfica do Rio Brilhante localiza-se na região sudoeste de Mato Grosso do Sul, ocupa uma área de 1.144.825 hectares. Está compreendida entre os paralelos

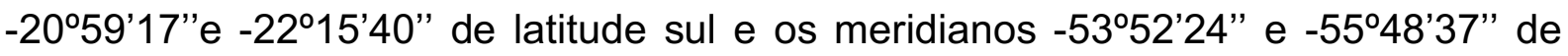
longitude oeste de Greenwich. Abarca territorialmente nove municípios inseridos total ou parcialmente em seus limites. O mapeamento das características ambientais da bacia hidrográfica do Rio Brilhante na forma de quadros de identificação de classes e mapas temáticos, sintetizando as informações dos elementos que a compõem, e, portanto, regem a funcionalidade da bacia, como a geologia, clima, solos, vegetação e o uso das terras, torna-se essencial a fim de demonstrar as dinâmicas territoriais vigentes. A caracterização de fato visa possibilitar o processo de articulação das informações a fim direcionar o processo de gestão do território.

$\mathrm{Na}$ contextualização da área de estudo, optou-se por organizar e sintetizar as informações do meio que possibilitassem identificar e caracterizar os principais fatores condicionantes que determinam a dinâmica nessa área (Figura 1). Sabe-se que há fatores físicos que determinam a implantação de canaviais em determinadas áreas associadas a maior produtividade, tais como as condições edafoclimáticas (tipo de solo, clima, precipitação, exposição solar e demanda de água) que interferem diretamente no comportamento fisiológico da cultura. Segundo Rosseto e Santiago (2008) a cultura da cana-de-açúcar deve dispor de condições climáticas bem marcadas entre o período seco e chuvoso, que permitem a planta crescer e acumular açúcar, além de boa disponibilidade de água, temperaturas elevadas e alto índice de radiação solar.

\subsection{Geologia}

O estado de Mato Grosso do Sul possui praticamente todo o seu território dividido entre o Planalto da Bacia Sedimentar do Paraná e a Planície do Pantanal MatoGrossense (Crepani et al., 2001). A área da bacia do rio Brilhante abrange duas formações geológicas, a formação Serra Geral (JKsg), que ocupa a maior parte da área da bacia $(84,5 \%)$ e a formação do grupo Caiuá $(\mathrm{Kc})$ detalhadas no Quadro I: 
Quadro I: Identificação e caracterização das classes de geologia.

\begin{tabular}{|c|c|l|c|c|}
\hline \multicolumn{2}{|c|}{ Classes } & \multicolumn{1}{c|}{ Características } & \multicolumn{1}{c|}{ Área } \\
\cline { 3 - 5 } Kc & $\begin{array}{l}\text { Grupo } \\
\text { Caiuá }\end{array}$ & $\begin{array}{l}\text { Localizada na porção nordeste do estado, historicamente, } \\
\text { essa unidade, e o vulcanismo alcalino associado, tem sido } \\
\text { interpretada como o ciclo final de evolução da Bacia do } \\
\text { Paraná. }\end{array}$ & 967.881 & 84,5 \\
\hline JKsg & $\begin{array}{l}\text { Distribui-se amplamente na região centro-sul do estado e em } \\
\text { áreas restritas às calhas dos principais rios da região } \\
\text { nordeste. Corresponde à fase que antecede a abertura do } \\
\text { Oceano Atlântico (Supersequência Gondwana III), constitui- } \\
\text { se pelo extravasamento de grande volume de lavas } \\
\text { basálticas continentais durante o Mesozoico. }\end{array}$ & 176.944 & 15,5 \\
\hline
\end{tabular}

Fonte: Lacerda Filho et al. (2006).

\subsection{Solos}

O tipo de solo predominante na bacia pertence a classe dos Latossolos, que cobrem mais de $95 \%$ da área da bacia, apresentando variação entre duas categorias diferentes: o Latossolo Vermelho Distrófico ( $L V d)$ e o Latossolo Vermelho Eutrófico (LVe). Para além destes, encontram-se nas margens dos principais rios o Gleissolo (GXve) e o Nitossolo (NV) (Quadro II).

Quadro II: Identificação e caracterização das classes de solos.

\begin{tabular}{|c|c|c|c|c|}
\hline \multirow{2}{*}{\multicolumn{2}{|c|}{ Classes }} & \multirow{2}{*}{ Características } & \multicolumn{2}{|c|}{ Área } \\
\hline & & & ha & $\%$ \\
\hline LVd & $\begin{array}{l}\text { Latossolo } \\
\text { Vermelho } \\
\text { Distrófico }\end{array}$ & $\begin{array}{l}\text { São solos geralmente muito intemperizados, profundos, } \\
\text { fortemente drenados, muito porosos e permeáveis. } \\
\text { Possuem baixa fertilidade natural, requerem aplicação de } \\
\text { corretivos e fertilizando para utilização agrícola. }\end{array}$ & 953.829 & 83,3 \\
\hline LVe & $\begin{array}{l}\text { Latossolo } \\
\text { Vermelho } \\
\text { Eutrófico }\end{array}$ & $\begin{array}{l}\text { Geralmente, são solos intemperizados, profundos, } \\
\text { fortemente drenados, muito porosos e permeáveis. Têm } \\
\text { alta fertilidade natural e as condições geográficas em que } \\
\text { ocorrem, aliadas à grande espessura, elevada } \\
\text { permeabilidade e ausência de impedimentos à } \\
\text { mecanização, conferem-lhes excelente potencial para } \\
\text { utilização intensiva. }\end{array}$ & 154.471 & 13,5 \\
\hline GXve & $\begin{array}{c}\text { Gleissolo } \\
\text { Háplicos Ta } \\
\text { Eutróficos }\end{array}$ & $\begin{array}{l}\text { São solos minerais, hidromórficos e comumente } \\
\text { encontrados nas áreas sob influência do lençol freático } \\
\text { próximo à superfície ou na superfície intermitente. De modo } \\
\text { geral, a utilização desses solos é dificultada pelas } \\
\text { condições de má drenagem e regime periódico de } \\
\text { inundação. Portanto, não são indicados para exploração } \\
\text { econômica, devido o seu alto grau de fragilidade. }\end{array}$ & 28.391 & 2,47 \\
\hline NV & $\begin{array}{l}\text { Nitossolo } \\
\text { Vermelho }\end{array}$ & $\begin{array}{l}\text { São solos mineirais, não- hidromórficos, possui coloração } \\
\text { mais escura e teor de óxidos de ferro mais elevados. } \\
\text { Nesses solos, verifica-se grande diversidade nas } \\
\text { propriedades de interesse para a fertilidade e uso agrícola. }\end{array}$ & 8.213 & 0,72 \\
\hline
\end{tabular}

Fonte: IBGE (2007); Santos et al. (2018). 


\subsection{Declividade}

Para elaboração do mapa de declividade utilizou-se imagens de radar do sensor ALOS/ PALSAR com resolução espacial de 12,5 metros utilizada para a construção do Modelo de Elevação do Terreno (MDE) e consequentemente obtenção das demais informações, adquirida no sistema Alaska Satellite Facility operado e distribuído pelo Earth Data/ National Aeronautics and Space Administration (NASA) (ASF, 2017).

O tratamento dos dados consistiu na reprojeção do sistema de coordenadas das imagens, além das operações de correção de falhas realizadas através da ferramenta Fill do ArcToolbox, no software ArcGIS. As características do relevo imprimem condições de baixa declividade em toda a extensão da bacia, portanto, para ressaltar as áreas com maior declive, foram estabelecidos intervalos de classes específicos para a bacia em estudo, os quais foram descritos no Quadro III.

Quadro III: Identificação e caracterização dos intervalos das classes de declividade.

\begin{tabular}{|c|c|c|}
\hline \multicolumn{2}{|c|}{ Declividade } & Características \\
\hline$\frac{\stackrel{\circ}{\frac{C}{\tilde{N}}}}{\frac{0}{\square}}$ & $0-3 \%$ & $\begin{array}{l}\text { Constitui-se de áreas planas ou quase planas, com escoamento } \\
\text { superficial lento. Há presença de áreas inundáveis e não apresenta } \\
\text { restrições aos tipos de uso, exceto aquelas previstas em lei, como } \\
\text { referentes às Áreas de Preservação Permanente (APP). }\end{array}$ \\
\hline 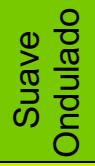 & $3-6 \%$ & $\begin{array}{l}\text { Formada por áreas com declives suaves e escoamento superficial, } \\
\text { predominantemente, lento ou médio. Não oferece impedimento para } \\
\text { ocupação antrópica. }\end{array}$ \\
\hline 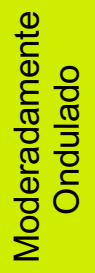 & $9-12 \%$ & $\begin{array}{l}\text { Áreas com leve inclinação, suscetíveis aos processos erosivos. O relevo } \\
\text { ondulado facilita o escoamento superficial, que se caracteriza como } \\
\text { médio ou rápido. Estas áreas necessitam de adoção de práticas } \\
\text { conservacionistas, a fim de evitar o comprometimento do quadro } \\
\text { ambiental }\end{array}$ \\
\hline $\begin{array}{l}\frac{0}{0} \\
\frac{\mathbb{D}}{\bar{T}} \\
\frac{0}{0} \\
\end{array}$ & $12-21 \%$ & $\begin{array}{l}\text { Abrangem áreas muito inclinadas ou colinas, onde o escoamento } \\
\text { superficial é caracterizado como rápido. São áreas que tendem à ação } \\
\text { dos processos erosivos e a ocupação deve ser acompanhada de } \\
\text { medidas conservacionistas }\end{array}$ \\
\hline 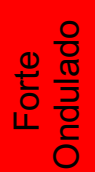 & $21-75 \%$ & $\begin{array}{l}\text { Compreende áreas de forte inclinação, cujo escoamento superficial é } \\
\text { bastante acelerado. A ocupação urbana é recomendada até } 30 \% \text { e deve } \\
\text { ser monitorada para que não ocorra comprometimento do quadro } \\
\text { ambiental }\end{array}$ \\
\hline
\end{tabular}

Fonte: Adaptado de Silva (2006)

\subsection{Clima}

A classificação de climática adotada é baseada na proposta de Zavattini (1992), elaborada especificamente para o estado de Mato Grosso do Sul. A bacia do rio Brilhante abrange duas zonas climáticas, caracterizadas pela alternância entre sistemas tropicais e polares ao longo do ano, típica na região (Zavattini, 1992). A área onde se localiza a bacia do rio Brilhante encontra-se exatamente na faixa de transição. 
Nela, a pluviosidade é muito bem marcada, ocorrendo chuvas intensas e convectivas no verão e chuvas frontais durante o inverno (Quadro IV). Essas informações sobre o clima são necessárias para definir a intensidade pluviométrica, relativa à pluviosidade anual e à duração do período chuvoso (Crepani et al., 2001).

Quadro IV: Identificação e caracterização das classes climáticas.

\begin{tabular}{|c|c|c|}
\hline \multicolumn{2}{|r|}{ Classes } & Características \\
\hline 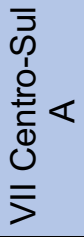 & $\begin{array}{l}\text { Serra de } \\
\text { Maracajú }\end{array}$ & $\begin{array}{l}\text { Nessa porção, as chuvas de outono-inverno alcançam } 400 / 450 \mathrm{~mm} \text { e } \\
\text { a estação mais chuvosa é a primavera. Ganha destaque nessa região } \\
\text { as temperaturas - bem baixas no outono-inverno - e a ocorrência de } \\
\text { geadas. }\end{array}$ \\
\hline 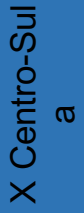 & $\begin{array}{l}\text { Porção Central - } \\
\quad \text { vales do } \\
\text { Ivinhema e Pardo }\end{array}$ & $\begin{array}{l}\text { Os índices pluviométricos nos vales do Ivinhema e Pardo } \\
\text { permanecem em torno de } 1.300 \mathrm{~mm} \text { e } 1.500 \mathrm{~mm} \text {. Nessa porção, } \\
\text { repete-se o mesmo quadro do Planalto Divisor (VII a), com chuvas de } \\
\text { primavera superiores às de verão e no período outono-inverno, } \\
\text { índices em torno de } 400 / 500 \mathrm{~mm} \text {. }\end{array}$ \\
\hline
\end{tabular}

Fonte: Adaptado de Zavattini (1992).

\subsection{Cobertura vegetal}

Na região sul do estado de Mato Grosso do Sul, além da presença do Cerrado, há relações fitogeográficas com o Cerrado, Floresta Atlântica e Chaco, que abrangem $65 \%, 8,9 \%$ e 3,8\% do território estadual, o que resulta em uma paisagem florística bastante diversificada (Mato Grosso do Sul, 2009).

Utilizando como referência o trabalho desenvolvido pelo IBGE (2012) - o Manual Técnico da Vegetação Brasileira e a classificação de Ribeiro e Walter (1998), as fitofisionomias consideradas para a bacia do rio Brilhante podem ser subdivididas em duas categorias: Floresta Estacional Semidecidual e Cerrado. De seguida é apresentada uma descrição sumária das principais classes de vegetação identificadas na região hidrográfica em estudo (Quadro V). 
Quadro V: Identificação e caracterização da cobertura vegetal.

\begin{tabular}{|c|c|c|c|c|}
\hline \multirow{2}{*}{\multicolumn{2}{|c|}{ Classes }} & \multirow{2}{*}{ Características } & \multicolumn{2}{|c|}{ Área } \\
\hline & & & ha & $\%$ \\
\hline $\mathrm{Fa}$ & $\begin{array}{l}\text { Floresta } \\
\text { Estacional } \\
\text { Semidecidual } \\
\text { Aluvial }\end{array}$ & $\begin{array}{l}\text { É encontrada em uma estreita faixa que ocupa as } \\
\text { margens dos cursos, sobretudo na parte alta da bacia } \\
\text { do Rio Brilhante. A estrutura desta fitofisionomia é } \\
\text { semelhante à da floresta ciliar de todos cursos de } \\
\text { água, só diferente de acordo com a posição geográfica }\end{array}$ & 198.734 & 17,4 \\
\hline Fs & $\begin{array}{l}\text { Floresta } \\
\text { Estacional } \\
\text { Semidecidual } \\
\text { Submontana }\end{array}$ & $\begin{array}{l}\text { Esse tipo de vegetação cobre as áreas de encosta do } \\
\text { Planalto Meridional, principalmente onde houve } \\
\text { derrame basáltico. São encontrados alguns poucos } \\
\text { fragmentos isolados desta formação nos municípios } \\
\text { de Rio Brilhante, Sidrolândia, Itaporã e Angélica. }\end{array}$ & 4.566 & 0,40 \\
\hline $\mathrm{Fm}$ & $\begin{array}{l}\text { Floresta } \\
\text { Estacional } \\
\text { Semidecidual } \\
\text { Montana }\end{array}$ & $\begin{array}{l}\text { A ocupação desta formação florestal é mais restrita, } \\
\text { uma vez que só se estabelece em áreas acima de } \\
500 \mathrm{~m} \text { de altitude. Na área de estudo ocorre em áreas } \\
\text { relativamente pequenas ou situadas em pontos } \\
\text { culminantes dos planaltos areníticos, como observado } \\
\text { um fragmento no município de Dourados na parte } \\
\text { oeste próximo à fronteira com Ponta Porã. }\end{array}$ & 2.053 & 0,18 \\
\hline Sd & Cerradão & $\begin{array}{l}\text { Esta fitofisionomia é restrita a áreas areníticas } \\
\text { lixiviadas com solos profundos, tendo sua ocorrência } \\
\text { associada a um clima tropical eminentemente } \\
\text { estacional. Na área da bacia do Rio Brilhante essa era } \\
\text { cobertura vegetal original dominante, atualmente são } \\
\text { poucas as áreas em que se encontra a vegetação } \\
\text { original. }\end{array}$ & 198.800 & 17,4 \\
\hline Sas & $\begin{array}{l}\text { Cerrado sentido } \\
\text { restrito }\end{array}$ & $\begin{array}{l}\text { Abrange o Cerrado Denso, Cerrado Típico, Cerrado } \\
\text { Ralo e Cerrado Rupestre. Essas fitofisionomias } \\
\text { caracterizam-se pela presença de árvores baixas, } \\
\text { inclinadas, tortuosas, com ramificações irregulares e } \\
\text { retorcidas. }\end{array}$ & 5.698 & 0,50 \\
\hline Pahs & $\begin{array}{l}\text { Formação } \\
\text { pioneira }\end{array}$ & $\begin{array}{l}\text { As áreas sazonais de influência aluvial revestidas por } \\
\text { esta vegetação distribuem-se em locais úmidos, } \\
\text { periódica ou permanentemente alagados, facultando } \\
\text { sucessivas alternâncias fisionômicas }\end{array}$ & 7.858 & 0,69 \\
\hline Acc & Agricultura & $\begin{array}{l}\text { Agricultura com culturas cíclicas (soja, trigo, feijão, } \\
\text { arroz e cana-de-açúcar). Áreas onde a cobertura } \\
\text { vegetal original foi substituída para dar lugar à } \\
\text { atividade agrícola. }\end{array}$ & 304.992 & 26,6 \\
\hline Ap & Pecuária & $\begin{array}{l}\text { Áreas em que a cobertura vegetal natural foi } \\
\text { substituída para dar lugar à atividade pecuária }\end{array}$ & 210.481 & 18,4 \\
\hline lu & $\begin{array}{c}\text { Influência } \\
\text { urbana }\end{array}$ & $\begin{array}{l}\text { Abrange outras formas de interferência humana e } \\
\text { incluem as áreas de influência urbana }\end{array}$ & 3.796 & 0,33 \\
\hline
\end{tabular}

Fonte: Adaptado de IBGE (2012).

A Figura 1 apresenta-se como a primeira síntese do uso e ocupação das terras da bacia em função de suas características edafoclimáticas. 

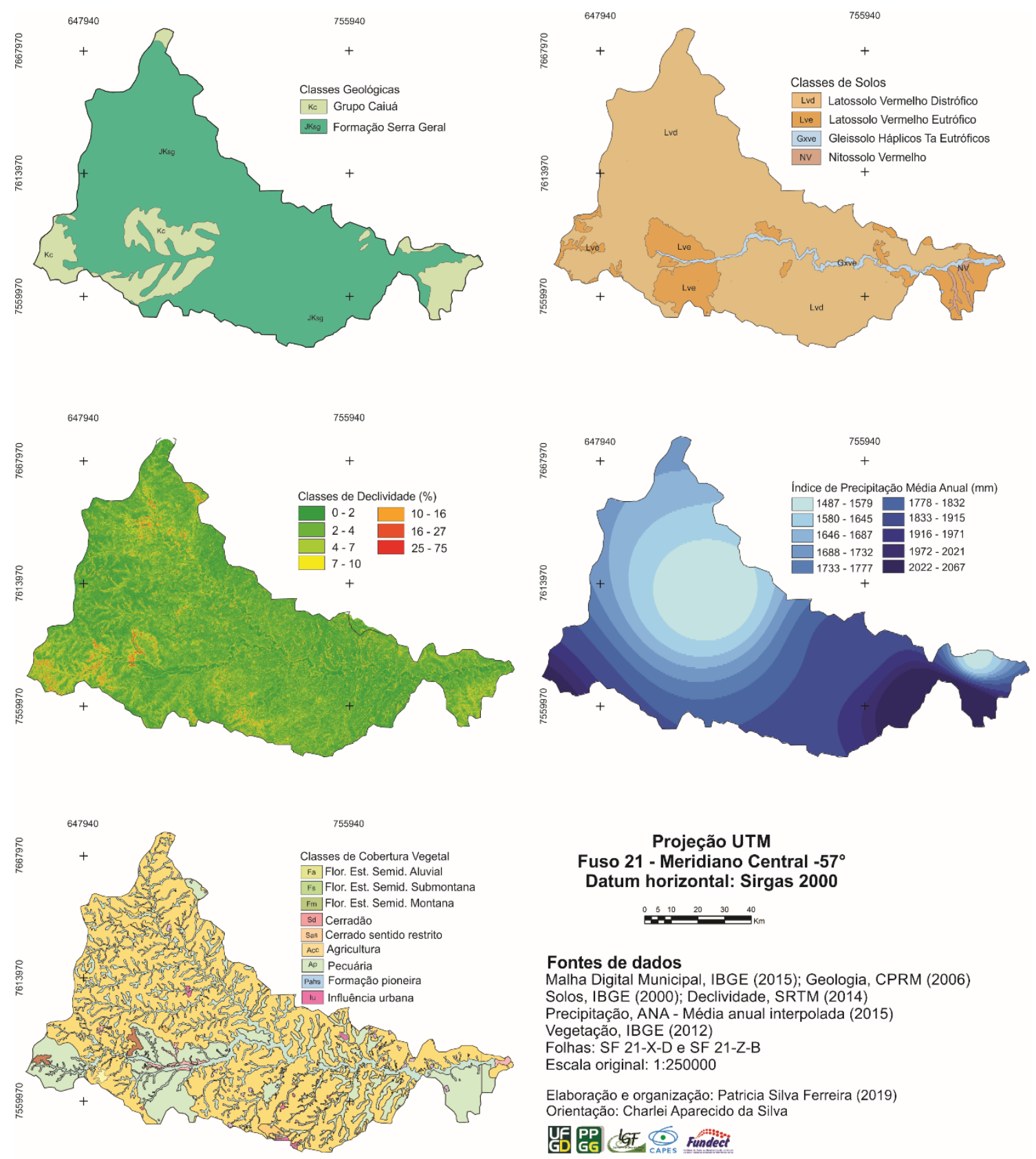

Figura 1: Síntese das informações das características físicas e bióticas da bacia do rio Brilhante MS.

\subsection{Uso e cobertura das terras}

Para o mapeamento do uso e cobertura das terras na bacia do Rio Brilhante foi utilizado o software livre SPRING 5.3 desenvolvido pelo INPE. Para a classificação automática empregou-se o método supervisionado por máxima verossimilhança (maxver) com limiar de 99,9\% de aceitação, nesse método o algoritmo utiliza amostras de treinamento, que devem ser representativas da imagem, para classificar a probabilidade de um determinado pixel pertencer a uma dada classe de acordo com atributos específicos, para tanto é necessário um conhecimento por parte do 
intérprete de alguns aspectos da área em estudo assim como da assinatura espectral dos objetos estudados.

O mapa de uso das terras e cobertura vegetal foi gerado a partir de técnicas de interpretação visual da resposta espectral dos alvos na imagem da série Landsat 8 sensor OLI (Operational Land Imager) (USGS, 2017), gerenciadas pela United States Geological Survey (USGS), na composição R5G6B4. Além dessas imagens, os dados foram verificados por meio de trabalhos de campo. Foram identificadas classes de vegetação natural, como fragmento florestais e de Cerrado e classes de uso antrópico (agricultura, pecuária, silvicultura, área urbana, etc) apresentadas no Quadro V:

Quadro V: Identificação e caracterização das classes de uso e cobertura das terras.

\begin{tabular}{|l|l|l|l|c|c|}
\hline \multicolumn{2}{|c|}{ Nível I } & \multicolumn{1}{c|}{ Nível II } & \multicolumn{1}{c|}{ Características } & \multicolumn{2}{c|}{ Área } \\
\cline { 2 - 6 } & \multirow{2}{*}{$\begin{array}{l}\text { Vegetação } \\
\text { natural }\end{array}$} & $\begin{array}{l}\text { Formação } \\
\text { Florestal }\end{array}$ & $\begin{array}{l}\text { Áreas de vegetação densa e } \\
\text { preservada. Geralmente, } \\
\text { correspondem a áreas de mata ciliar, } \\
\text { resquícios da Floresta Estacional } \\
\text { Semidecidual e alguns fragmentos de } \\
\text { Cerrado. }\end{array}$ & 69.141 & 6,04 \\
\hline Acc & \multirow{2}{*}{ Agricultura } & $\begin{array}{l}\text { Anual e } \\
\text { Perene }\end{array}$ & $\begin{array}{l}\text { Áreas destinadas à atividade agrícola } \\
\text { com cultivos temporários (soja, milho, } \\
\text { trigo, feijão, arroz, cana-de-açúcar, } \\
\text { etc). }\end{array}$ & 920.434 & 80,4 \\
\hline Ap & \multirow{2}{*}{ Pastagem } & $\begin{array}{l}\text { Campos naturais ou plantados } \\
\text { atribuídos a criação de gado de corte } \\
\text { ou leiteiro. }\end{array}$ & 27.576 & 2,41 \\
\hline Ag & Agropecuária & $\begin{array}{l}\text { Formações vegetais secundárias que } \\
\text { servem para o pastoreio do gado em } \\
\text { criação extensiva }\end{array}$ & 7.115 & 0,62 \\
\hline Re & Silvicultura & $\begin{array}{l}\text { Áreas de reflorestamento (eucalipto ou } \\
\text { pinus) para exploração econômica } \\
\text { madeireira. }\end{array}$ & 2.156 & 0,19 \\
\hline Se & Solo exposto & $\begin{array}{l}\text { Geralmente, são áreas de recente } \\
\text { colheita ou terras aradas em preparo } \\
\text { para o cultivo. }\end{array}$ & 832 & 0,07 \\
\hline lu & Influência urbana & $\begin{array}{l}\text { Compreende porções de perímetros } \\
\text { urbanos }\end{array}$ & 4.001 & 0,35 \\
\hline Ca & Corpos d'água & $\begin{array}{l}\text { Corresponde a superfícies de rios, } \\
\text { lagos e represas }\end{array}$ & 6.703 & 0,59 \\
\hline
\end{tabular}

\section{Resultados e Discussões}

O mapa de uso das terras e cobertura vegetal, um dos objetos centrais da análise, evidencia a dinâmica territorial recente da bacia do rio Brilhante. É observado que o uso das terras se dá quase exclusivamente fins de atividades econômicas primárias, agricultura e pecuária, de monoculturas. Isso decorre das ações desenvolvimentistas priorizadas pelos setores econômicos incentivados por políticas públicas em diversos níveis (municipal, estadual e federal). As atividades do setor agropecuário merecem destaque, observa-se a supressão de extensas áreas de vegetação nativa ao longo do tempo em função da ampliação das áreas de monoculturas. 
Prioritariamente o uso da terra tanto desta, e, de outras regiões de Mato Grosso do Sul, está intrinsecamente ligado às relações socioeconômicas e políticas que o modelo de desenvolvimento do estado. As áreas de cobertura vegetal natural que ainda restam podem ser atribuídas às restrições vigentes na legislação ambiental que abarcam as áreas protegidas, tais como: APP (Áreas de Preservação Permanente), reserva legal $(R L)$ e terras indígenas. Na bacia em estudo localizam-se quatro terras indígenas, que compreendem juntas, um total de 17.477 hectares e três unidades de conservação, sendo duas pertencentes à categoria de Reserva do Particular do Patrimônio Natural (RPPN) e uma à Área de Proteção Ambiental (APA) que, somadas, totalizam 11.405 hectares, apresentadas mais adiante na Figura 5, além das áreas preservadas na forma de APP e RL. Soma-se, mesmo que em menor grau, as áreas que impõem limitações as atividades agrícolas, são elas: áreas alagadas e/ou sujeitas à inundação e com alto nível de declive. As comparações das (Figuras 1 e 2) subsidiam essas conclusões.

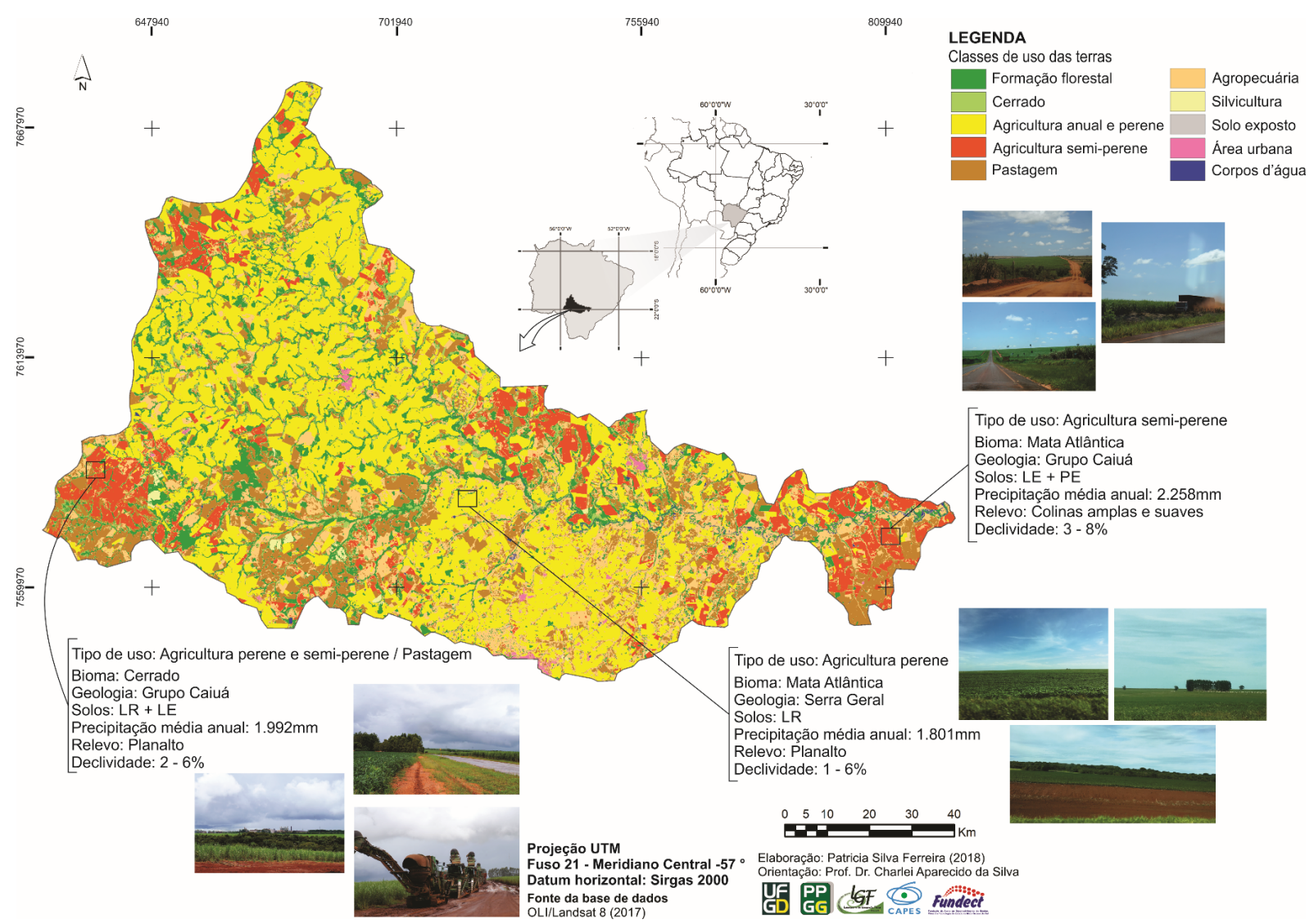

Figura 2: Uso e cobertura das terras na bacia do Rio Brilhante e as dinâmicas territórias recentes

Observa-se de fato que as áreas de vegetação natural se encontram fragmentadas, isoladas e em muitas situações bem próximas onde o uso predominante é a agricultura, o que acarreta, portanto, grande pressão dessa atividade sobre os remanescentes florestais (Figura 2), devido, principalmente ao efeito de borda, que se caracteriza como o conjunto de alterações físicas nos processos ecológicos sofridos 
pelo fragmento em área de borda (Metzger, 1999; Laurance et al., 2002, Newton, 2007). Para Laurance et al., (2006) esse é o principal impacto sobre fragmentos de florestas tropicais, pois expõe os organismos localizados nos limites do fragmento a diferentes condições do ecossistema do entorno.

Além das características físicas favoráveis, reitera-se que aspectos políticoeconómicos, como os incentivos fiscais concedidos pelo poder público na esfera federal, estadual e municipal, o baixo custo das terras para arrendamento ou compra e o suporte logístico para escoamento da produção facilitaram e foram determinantes para expansão do setor sucroenergético nessa área.

A dinâmica territorial que tem ocorrido, no que se refere a expansão da cana-deaçúcar, é verificada também em outros estudos, como em Pereira (2007), Azevedo (2008), Backes (2009), Domingues (2010), Pinto Junior (2014), Ferreira (2016), ou Ferreira e Silva $(2016 ; 2017)$, e se apresenta como uma tendência crescente, considerando que até o início dos anos 2000 essa região não possuía nenhuma representatividade como produtor de cana-de-açúcar e derivados (Figuras 3 e 4).

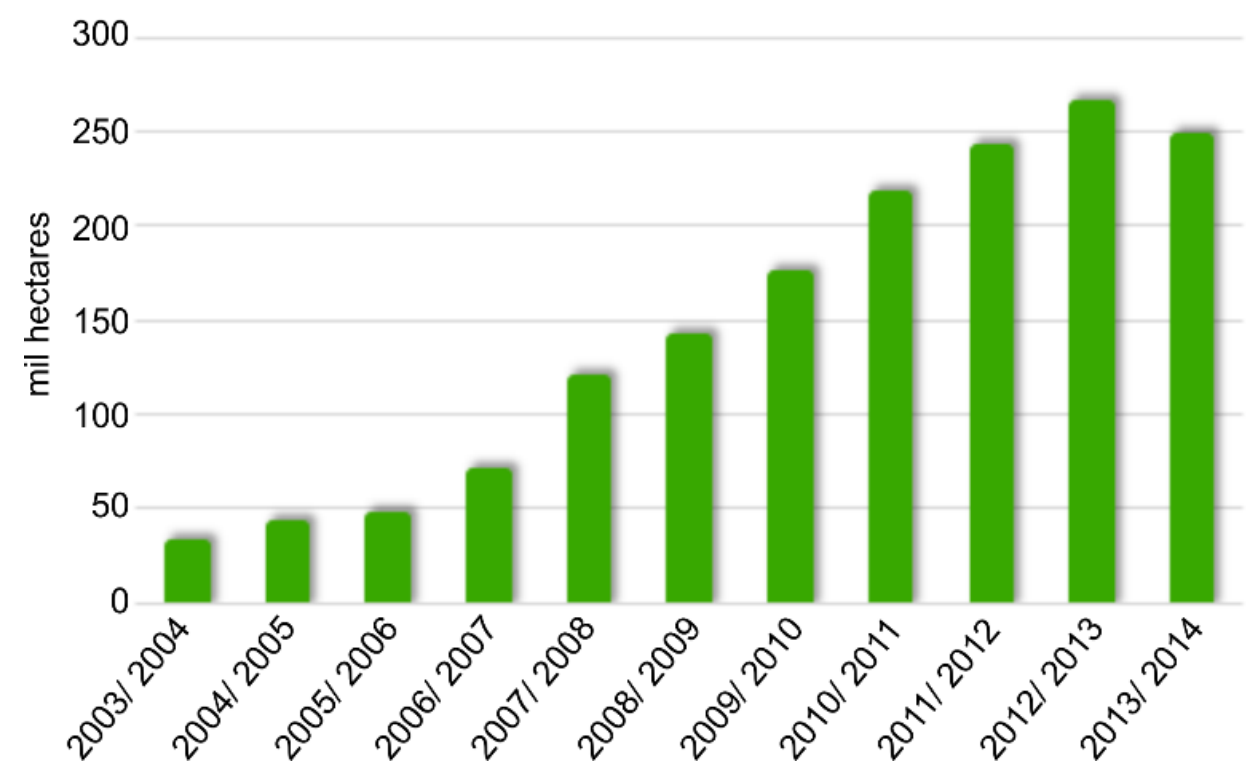

Figura 3: Evolução da área plantada com cana-de-açúcar nos municípios da bacia do rio Brilhante/MS.

Fonte: Produção Agrícola Municipal (PAM), 2014.

Organização: Ferreira (2016).

Ao considerarmos o ordenamento da expansão da cana-de-açúcar delimitada pelo Zoneamento Agroecológico da Cana-de-Açúcar (ZAE) (EMBRAPA, 2009) verificamos que nessa região há a existência de solos com boa e regular aptidão agrícola e a potencialidade aparece, predominantemente na condição média para alta, não sendo encontrada na classe de baixa aptidão (Tabela I). Tal conjuntura explica a atração de investimentos do setor sucroenergético nessa área e a consolida como zona de expansão da agricultura e pecuária. 
Além disso, a produção da cana-de-açúcar é uma atividade diferenciada de outras culturas, pois a distância entre as áreas de plantio da cultura e a agroindústria não deve ultrapassar $30 \mathrm{~km}$, usualmente, em regiões produtoras tradicionais utiliza-se uma distância econômica padrão da produção até a indústria de 15 a 20 km, o que de certa forma, aumenta a pressão por determinadas áreas (Figura 4).
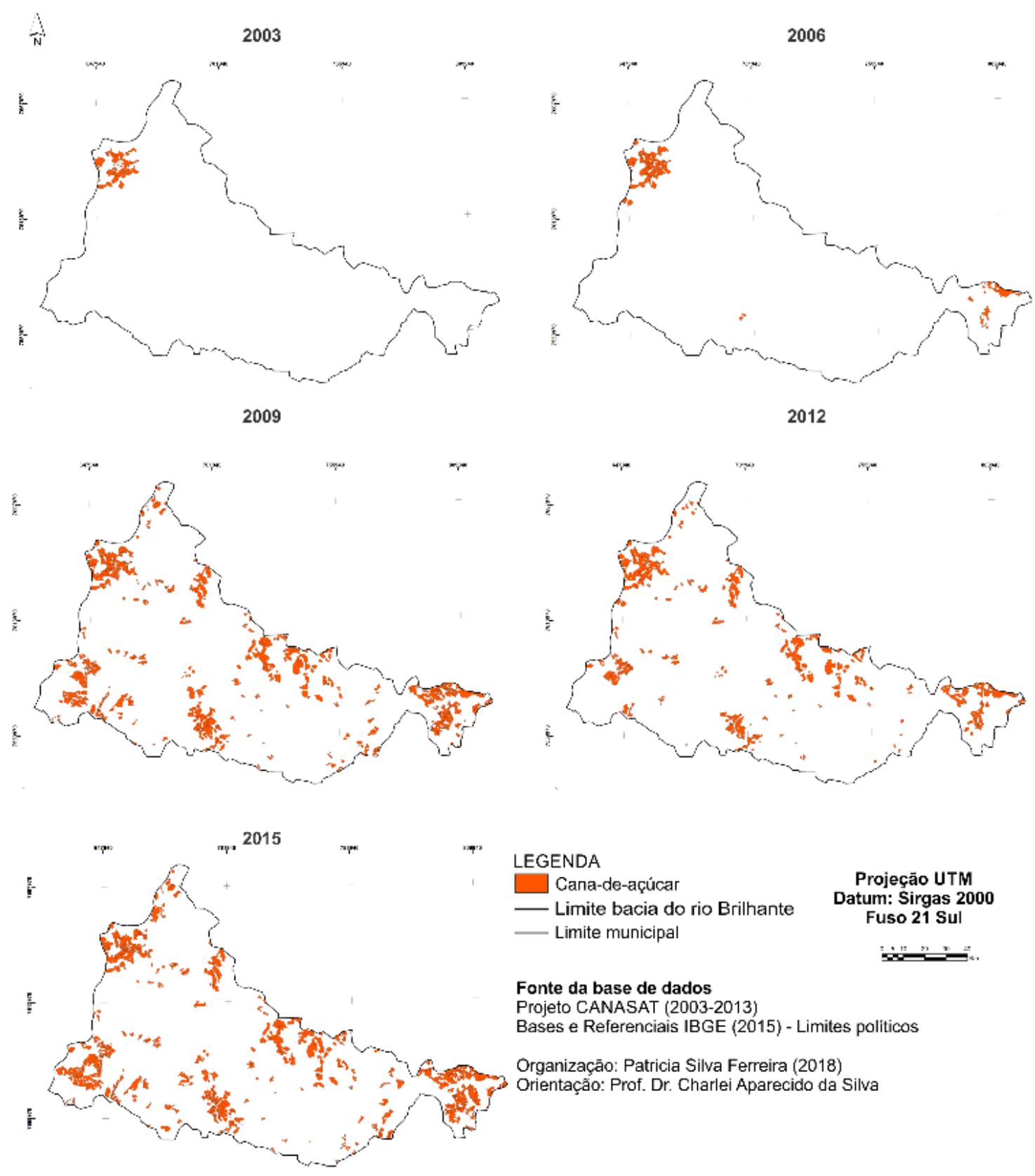

Figura 4: Evolução temporo-espacial da área plantada com cana-de-açúcar na bacia do rio Brilhante. 
Tabela I: Áreas aptas a expansão do cultivo da cana-de-açúcar na bacia do Rio Brilhante-MS.

\begin{tabular}{l|l|r|c}
\hline \multicolumn{1}{c|}{ Uso } & Aptidão & Área (hectares) & $\mathbf{( \% )}$ \\
\hline \multirow{3}{*}{ Agrícola } & Alta & 71.182 & 6,2 \\
\cline { 2 - 4 } & Média & 617.706 & 53,9 \\
\cline { 2 - 4 } & Baixa & 0 & - \\
\hline \multirow{3}{*}{ Pecuária } & Alta & 86.255 & 7,5 \\
\cline { 2 - 4 } & Média & 105.603 & 9,3 \\
\cline { 2 - 5 } & Baixa & 0 & - \\
\hline Não classificada & & 264.079 & 23,1 \\
\hline
\end{tabular}

As áreas indicadas para a expansão da cana-de-açúcar no ZAE (Figura 5) abrangem aquelas que atualmente são ocupadas por produção agrícola intensiva a semiintensiva, lavouras perenes e anuais e pastagens, excluindo a produção de cana-deaçúcar (áreas não classificadas) nos biomas Amazônia e Pantanal e na Bacia do Alto Paraguai, terras indígenas, áreas com cobertura vegetal nativa, remanescentes florestais, áreas de proteção ambiental, mangues, dunas, escarpas e afloramentos de rocha, reflorestamento, áreas urbanas e de mineração, áreas com declividade superior a $12 \%$, considerando a premissa da mecanização no âmbito da proibição da queima dos canaviais para áreas de expansão.

Com essas informações é possível verificar que a parte alta e baixa da bacia são as áreas mais propícias ao cultivo da cana-de-açúcar e ao sobrepor essa camada (layer) com as áreas já ocupadas efetivamente por pela cultura verifica-se que tal expansão vem ocorrendo à custa da conversão de áreas agrícolas e não de áreas de pastagem degradada, como sugere o discurso político.
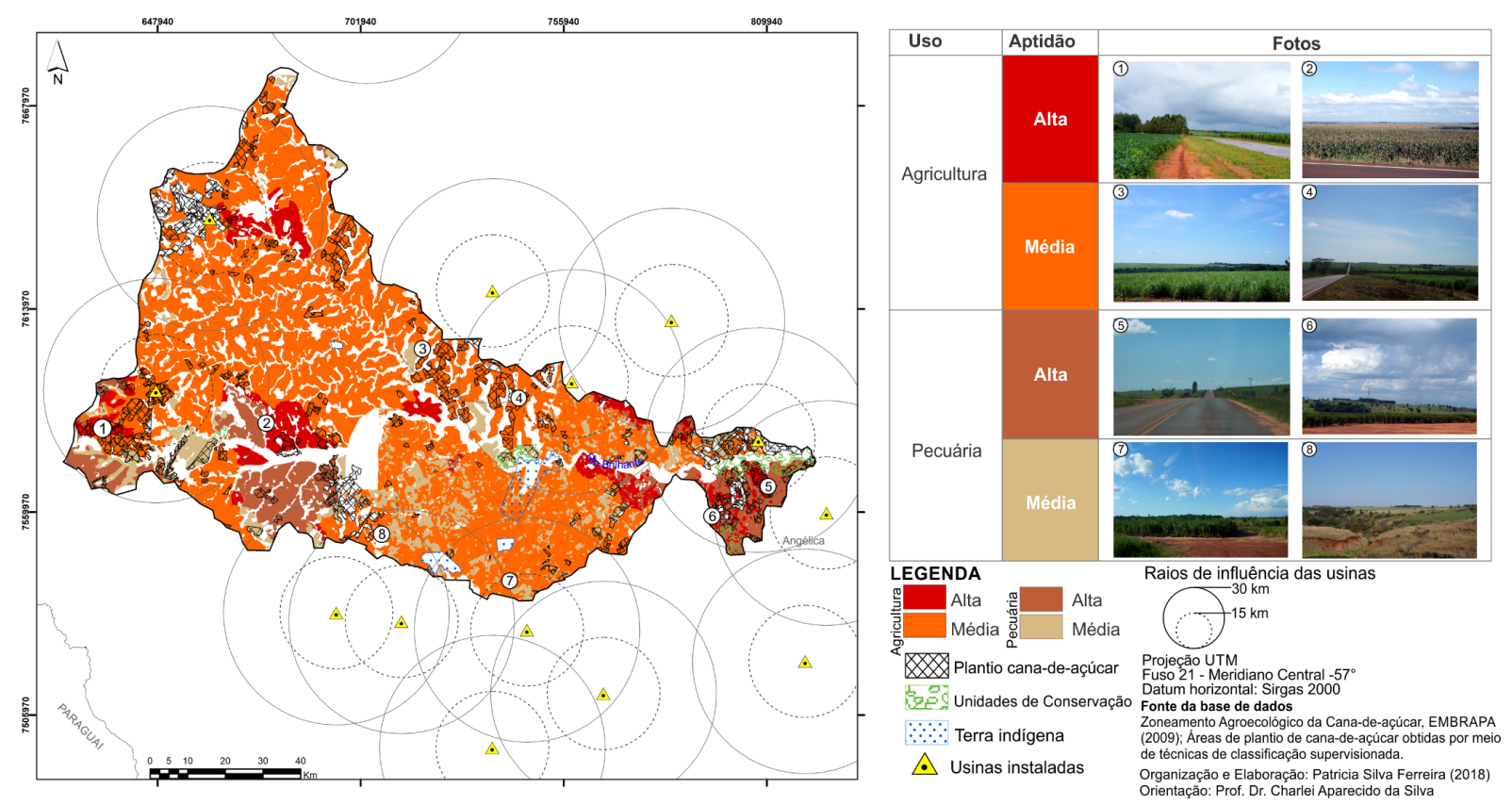

Figura 5: Áreas indicadas para expansão da cana-de-açúcar a partir do ZAE. 


\section{Considerações Finais}

As propriedades rurais inseridas na bacia do rio Brilhante historicamente foram ocupadas, principalmente, pelo binômio soja/milho. O avanço do plantio de cana-deaçúcar na região centro-sul do estado de Mato Grosso do Sul traz à tona novamente preocupações no que tange aos impactos socioambientais, sobretudo nos pequenos municípios, os quais não dispõem de infraestruturas necessárias e nem planejamento para dar suporte a empreendimentos de grande porte exigidos pelo setor sucroenergético.

O estudo evidencia as condições potenciais dessa bacia para intensificação da atividade sucroenergética, a qual necessita de grandes extensões de terra para o plantio da cana-de-açúcar. A expansão motivada por políticas públicas, incentivos fiscais e o baixo preço das terras na forma de arrendamentos estão atreladas às características edafoclimáticas favoráveis, essencialmente um relevo plano, de baixa declividade, associada às características físico-estruturais do Latossolo, com disponibilidade de água. Soma-se a intensificação da mecanização no processo produtivo e a saturação de áreas cultivadas com cana-de-açúcar no Estado de São Paulo e Goiás, esses os maiores produtores da cultura no Brasil.

Os cenários postos por ciclos econômicos baseados em monoculturas e concentração fundiária no Brasil manifestam-se no surgimento de áreas que acumulam desigualdade social e impactos socioambientais de diversas ordens e magnitude. Dessa forma, evidencia-se que a supressão e a diminuição das áreas de vegetação nativa, bem como a pressão sob os remanescentes protegidos pela legislação brasileira, expõem a necessidade da instituição e implementação de instrumentos de regulação efetivos por parte dos órgãos gestores e fiscalizadores. Observa-se que as premissas do planejamento ambiental podem se constituir como instrumentos de normatização e direcionar o uso das terras na bacia do rio Brilhante, mas essa condição deve-se fazer presente no âmbito dos princípios públicos de gestão territorial. Deve haver clareza quanto a opção da ocupação exclusiva da cana-deaçúcar e precaver-se dos potenciais danos socioambientais desta atividade sobre o equilíbrio ambiental da bacia, especialmente na manutenção dos recursos hídricos e remanescentes florestais, aspeto urgente e necessário. Em um momento histórico no qual as pautas e princípios ambientais, de sustentabilidade, no Brasil estão sendo substituídas por visões obtusas e imediatistas, a discussão ora posta torna-se das mais importantes a fim de qualificar e apresentar instrumentos claros, objetivos, para a gestão do território sul mato-grossense.

\section{Bibliografia}

ASF, Alaska Satellite Facility (2017). MapReady. Consultado em 10 de abril de 2017, em https://search.asf.alaska.edu.

Azevedo, J. R. N. (2008). Expansão da agroindústria canavieira no Mato Grosso do Sul: relação capital $x$ trabalho e reconfiguração espacial. Dissertação de Mestrado em Geografia. Universidade Federal da Grande Dourados. 
Backes, T. R. (2009). O capital agroindustrial canavieiro no Mato Grosso do Sul e a internacionalização da produção. Dissertação de Mestrado em Geografia. Universidade Federal da Grande Dourados.

Bertrand, G. (2004). Paisagem e geografia física global - esboço metodológico. $R A$ 'E GA, 8, 141-152. Consultado em 23 maio 2015, em http://ojs.c3sl.ufpr.br/ojs2/index.php/raega/article/viewFile/3389/2718.

Crepani, E., Medeiros, J. S. de, Hernandez, P., Florenzano, T. G, Duarte, V., Barbosa, C. C. F. (2001). Sensoriamento remoto e geoprocessamento aplicados ao Zoneamento Ecológico-Econômico e ao ordenamento territorial. São José dos Campos: SAE/INPE.

Christofoletti, A. (1979). Análise de sistemas em Geografia. São Paulo: Editora Hucitec.

Christofoletti, A. (1999). Modelagem de sistemas ambientais. $1^{\circ}$ Edição. São Paulo: Edgard Blucher.

Domingues, A. T. (2010). A terrritorialização do grupo agroindustrial canavieiro Louis Dreyfus no Mato Grosso do Sul. Dissertação de Mestrado em Geografia. Universidade Federal da Grande Dourados.

Ferreira, O. S. (2016). Dinâmicas territoriais: uso e ocupação das terras da bacia hidrográfica do Rio Brilhante - MS, a expansão da cana-de-açúcar. Dissertação de Mestrado em Geografia. Universidade Federal da Grande Dourados.

Ferreira, P. S.; Silva, C. A. (2016). A expansão da cana-de-açúcar na bacia hidrográfica do Rio Brilhante, Mato Grosso do Sul: o uso da técnica de NDVI como instrumento para evidenciar dinâmicas territoriais. Revista Geografares, 23, 66-81. https://doi.org/10.7147/GEO23.12340.

Ferreira, P. S., Silva, C. A. (2017). A expansão das lavouras de cana-de-açúcar na bacia hidrográfica do Rio Brilhante/MS e na área de influência das usinas sucroenergéticas. Em: Planejamento e Análises Ambientais (pp. 29-44). Tupã-SP: ANAP.

Frata, A. M., Faria, A. B. (2008). A cana-de-açúcar na região hidrográfica do rio Paraná e a produção de grãos, a pecuária e a cana na sub-bacia do rio Ivinhema. Campo Grande-MS: Ecoa.

Fitz, P. R. (2008). Geoprocessamento sem complicação. São Paulo: Oficina de Textos.

INPE (2014). Instituto Nacional de Pesquisas Espaciais. Sistema de Processamento de Informações Georreferenciadas (SPRING). São José dos Campos. Versão 5.3. Consultado em 16 de março de 2015, em http://www.dpi.inpe.br/spring/.

IBGE (2007). Manual Técnico em Pedologia. Rio de Janeiro: IBGE, Manuais Técnicos em Geociências, 2. ed.

IBGE (2012). Manual Técnico da Vegetação Brasileira. Rio de Janeiro: IBGE, Manuais Técnicos em Geociências.

Lacerda Filho, J. V., Brito, R. S. C., Silva, M. G., Oliveira, C. C., Moreton, L. C., Martins, E. G., Lopes, R. C., Lima, T. M., Larizzatt, J. H., Valente, C. R. (2006). Geologia e Recursos Minerais do Estado de Mato Grosso do Sul. Goiânia: Programa Geologia do Brasil executado em convênio Serviço Geológico do Brasil (CPRM); Secretaria de Estado da Produção e do Turismo de Mato Grosso Do Sul (SEPROTUR/MS) e; Empresa de Gestão de Recursos Humanos e Patrimônio de Mato Grosso do Sul (EGRHP/ MS). 
Laurance, W. F., Lovejoy, T. E., Vasconcelos, H. L., Bruna, E. M., Didham, R. K., Stouffer, P. C., Gascon, C., Bierregaard, R. O., Laurance, S. G., Sampaio, E. (2002). Ecosystem decay of Amazonian forest fragments: a 22-year investigation. Society for Conservation Biology, 16, 605-618. https://doi.org/10.1046/j.1523-1739.2002.01025.x.

Laurance, W. F., Nascimento, H. E., Laurance, S. G., Andrade, A. C., Fearnside, P. M., Ribeiro, J. E., Capretz, R. L. (2006). Rain forest fragmentation and proliferation of successional trees. Ecology, 87(2), 469-482. https://doi.org/10.1890/05-0064.

Manzatto, C. V., Assad, E. D., Bacca, J. F. M., Zaroni, M. J., Pereira, S. E. M. (orgs) (2009). Zoneamento agroecológico da cana-de-açúcar. Rio de Janeiro: Embrapa Solos.

Mateo-Rodriguez, J. M. (2002). Geografía de los paisajes. Primera parte: paisajes naturales. La Habana: Editorial Universitaria de La Habana.

Mateo-Rodríguez, J. M. (2005). La cuestión ambiental desde una visión sistémica. Revista Ideas Ambientales, 2, 1-35.

Mateo-Rodriguez, J. M., Silva, E. V., Leal, A. C. (2011). Planejamento ambiental de bacias hidrográficas desde a visão da geoecologia das paisagens. In: Figueiró, A. S., Foleto, E. (orgs). Diálogos em geografia física. Santa Maria: Ed. UFSM.

Mato Grosso do Sul (2009). Zoneamento Ecológico Econômico do Estado de Mato Grosso do Sul. Consultado em 23 de maio de 2015, em http://www.semac.ms.gov.br/zeems/.

Metzger, J. P. (1999). Estrutura da paisagem e fragmentação: análise bibliográfica. Anais da Academia Brasileira de Ciências, 71( 3-I), 445-463.

Monteiro, C. A. F. (2000). Geossistemas: a história de uma procura. São Paulo: Contexto.

Newton, A. C. (2007). Forest ecology and conservation: a handbook of techniques. Oxford: Oxford University Press.

Pereira, M. C. (2007). A expansão da cadeia sucroalcooleira em Mato Grosso do Sul, dinâmica e determinantes. Dissertação de Mestrado em Agronegócio. Multinstitucional Universidade Federal de Mato Grosso do Sul, Universidade de Brasília e Universidade Federal de Goiás.

Pinto Junior, S. C., Silva, C. A., Berezuk, A. G. (2014). As transformações da paisagem na Unidade de Planejamento e Gerenciamento Ivinhema a partir da expansão da cana-deaçúcar. Revista Eletrônica da Associação dos Geógrafos Brasileiros, 19 (11), 28-55. https://periodicos.ufms.br/index.php/RevAGB/article/view/420/216.

Quantum Gis Development Team (2015). Quantum GIS Geographic Information System. Open Source Geospatial Foundation Project,Versão 2.12.3 "Lyon". Consultado em http://qgis.osgeo.org.

Ribeiro, J. F., Walter, B. M. T. (1998). Fitofisionomias do bioma Cerrado. Em Sano, S. M., Almeida, S. P. (orgs). Cerrado: ambiente e flora (pp 89-166). Planaltina: Embrapa Cerrados.

Rossetto, R., Santiago, A. D. (2008). Plantio da cana-de-açúcar. EMBRAPA: Agência Embrapa de Informação Tecnológica. Consultado em 09 de março de 2016, em http://www.agencia.cnptia.embrapa.br/gestor/cana-deacucar/arvore/CONTAG01 33 711200516717.html. 
Ross, J. L. S. (1994). Análise Empírica da Fragilidade dos Ambientes Naturais e Antropizados. $\begin{array}{llll}\text { Revista do Departamento de Geografia, } & \text { 8, }\end{array}$ https://doi.org/10.7154/RDG.1994.0008.0006.

Ross, J. L. S. (1995). Análises e Sínteses na Abordagem Geográfica da Pesquisa para o Planejamento Regional. Revista do Departamento de Geografia, 9, 65-75. https://doi.org/10.7154/RDG.1995.0009.0006.

Santos, H. G. et al., (2018). Sistema Brasileiro de Classificação de Solos. Brasília, DF: Embrapa, 5 ed.

Santos, R. F. (2004). Planejamento Ambiental: teoria e prática. São Paulo: Oficina dos Textos.

Silva, C. A. (2006). Análise sistêmica, turismo de natureza e planejamento ambiental de Brotas: proposta metodológica. Tese de Doutorado em Geociências. Universidade Estadual de Campinas.

Sotchava, V. B. (1978). Por uma teoria de classificação de geossistemas de vida terrestre. São Paulo: IGEO/USP.

Tricart, J. I. (1977). Ecodinâmica. Rio de Janeiro: IBGE, Diretoria Técnica, SUPREN.

Troppmair, H., Galina, M. H. (2006). Geossistemas. Mercator, 10 (5), 79-89. http://www.mercator.ufc.br/index.php/mercator/article/view/69/44.

Zavattini, J. A. (1992). Dinâmica climática no Mato Grosso do Sul. Rio Claro: Geografia, 2 (17), 65-91.

USGS. United States Geological Survey (2017). Imagem LANDSAT 8. Sensor OLI. Canais 1,2,3,4,5,6 e pan. Órbita 224 e 225 ponto 075. De 09 de julho de 2017 e 31 de julho de 2015. Disponível em: http://earthexplorer.usgs.gov/.

\section{Agradecimentos}

Os autores agradecem às agências de fomento, a Coordenação de Aperfeiçoamento de Pessoal de Nível Superior (CAPES) e a Fundação de Apoio ao Desenvolvimento do Ensino, Ciência e Tecnologia do Estado de Mato Grosso do Sul (Fundect), pelo apoio financeiro na forma de bolsa de estudo concedida à primeira autora. Ao Programa de Pós-Graduação em Geografia (PPGG) e ao Laboratório de Geografia Física (LGF) da UFGD, pelo apoio logístico.

\section{Financiamento}

Este trabalho recebeu financiamento como bolsa de estudos da Capes (www.capes.gov.br) e Fundect (www.fundect.ms.gov.br).

Artigo recebido em / Received on: 14/08/2019

Artigo aceite para publicação em / Accepted for publication on: 17/10/2019 